\title{
THE MAIN RESEARCH DIRECTIONS IN CA ASSEMBLY ANALYSIS AND ASSEMBLY WORKSTATION DESIGN
}

\author{
Štefan VÁCLAV ${ }^{1}, K_{\text {atarína SENDERSKÁ }}^{2}$, Albert MAREŠ² \\ ${ }^{1}$ SLOVAK UNIVERSITY OF TECHNOLOGY IN BRATISLAVA, \\ FACULTY OF MATERIALS SCIENCE AND TECHNOLOGY IN TRNAVA, \\ INSTITUTE OF PRODUCTION TECHNOLOGIES, \\ Ulica JÁNA BotTu 2781/25, 91724 TRNAVA, SLOVAK REPUBliC \\ ${ }^{2}$ TECHNICAL UNIVERSITY OF KOŠICE, \\ FACULTY OF MECHANICAL ENGINEERING, \\ LETNÁ 9, 04001 KoŠICE, SLOVAK REPUBLIC \\ e-mail: stefan.vaclav@stuba.sk, katarina.senderska@tuke.sk, albert.mares@tuke.sk \\ Received: 29.05.2018, Accepted: 28.06.2018, Published: 19.09.2018
}

\begin{abstract}
The article deals with main research direction in the field of assembly process analysis and assembly workstation design. The basic applied methods and tool in the mentioned research direction are a part of digital factory concept. The paper presents the application of knowledge system for DFA analysis, computer aided assembly, workstation design and application of virtual reality.
\end{abstract}

\section{Key words}

Assembly, DFA, CAx systems, virtual reality

\section{INTRODUCTION}

In manufacturing, assembly operations play a significant role, and are often also a bottleneck of the manufacturing process. This is because, depending on the type of production in these operations, manual work is predominant. E.g. in automotive production we can talk about $100 \%$ automation in most of series production, but manual work is still prevailing in the final assembly of cars. This is due to the complexity of operations whose automation would now be extremely demanding both technically and financially. Therefore, due attention must be paid to assembly operations from the design stage, through the design of the assembly operations to the final dismantling of the product after the end of its life cycle. In this area, CA technology is very helpful in enabling early detection of problems at the design stage, thereby reducing the cost of additional troubleshooting at a later stage. CA technologies are also applicable to various methods of assembly process analysis, video analysis and virtual reality that allow you to identify bottlenecks in the assembly process and then design and take corrective action. 


\section{DESIGN FOR ASSEMBLY ANALYSIS}

For the product design analysis from the point of view assembly was proposed a method issued from the decision analysis. The basis of this approach is a set of rules and recommendations for the assembly and the collection of questions. The analysis and evaluation are divided into four steps: product, parts, joints and assemblies. The method assumes to answer five main questions in all four steps. The "answer" is a point evaluation and a creative proposal that can be inspired so by existing stored proposal for similar products, parts, joints or assemblies as by the set of rules and recommendations.

The developed access tool is dedicated to the analysis of the medium complex mechanical products and was tested at several products.

Main functions:

- Refill and modify the contained rules and recommendations.

- Evaluate the questions/criteria selection and definition.

- Define the point values for decision analysis.

- Product/products analysis.

- Analysis of the parts, joints and subassemblies.

The concept (1) enables also to modify the material, part symmetry, kind of the joint and other parameters of assortment. The whole system is opened for further modification, for instance, as a comparison of two or more variants of the products, evaluation from the point of view disassembly etc. For better information, the system can include also drawings, 3D models or photographs of the products, parts, joints and subassemblies. Figure 1 shows the main screen for the product data input.

Some default reports were created in this system. From the data and analysis results contained in this system, we can created various reports according to the requirements.

The basis of this approach is a list of rules and recommendation for product design from the point of view assembly. The system is designed so that at the time of using the system, the rules, recommendation and examples can be continuously refilled. Figure 1 shows the screen with the list of rules and appropriate examples.

The questions can also be modified or changed. By changes in this filed must be clearly that the obtained results can be depended on the putted questions. This must be considered in the case of comparison of such results obtained by using different questions.

Experience with creation and application of the developed tool to product design analysis from the point of view assembly shows that it is one of the possible directions in the design for assembly supporting. The tool can be easily used, modified and refilled. It is also important, that this tool can be used to store and manage any previously proposed solution of a part, joint assemblies or product changes. 


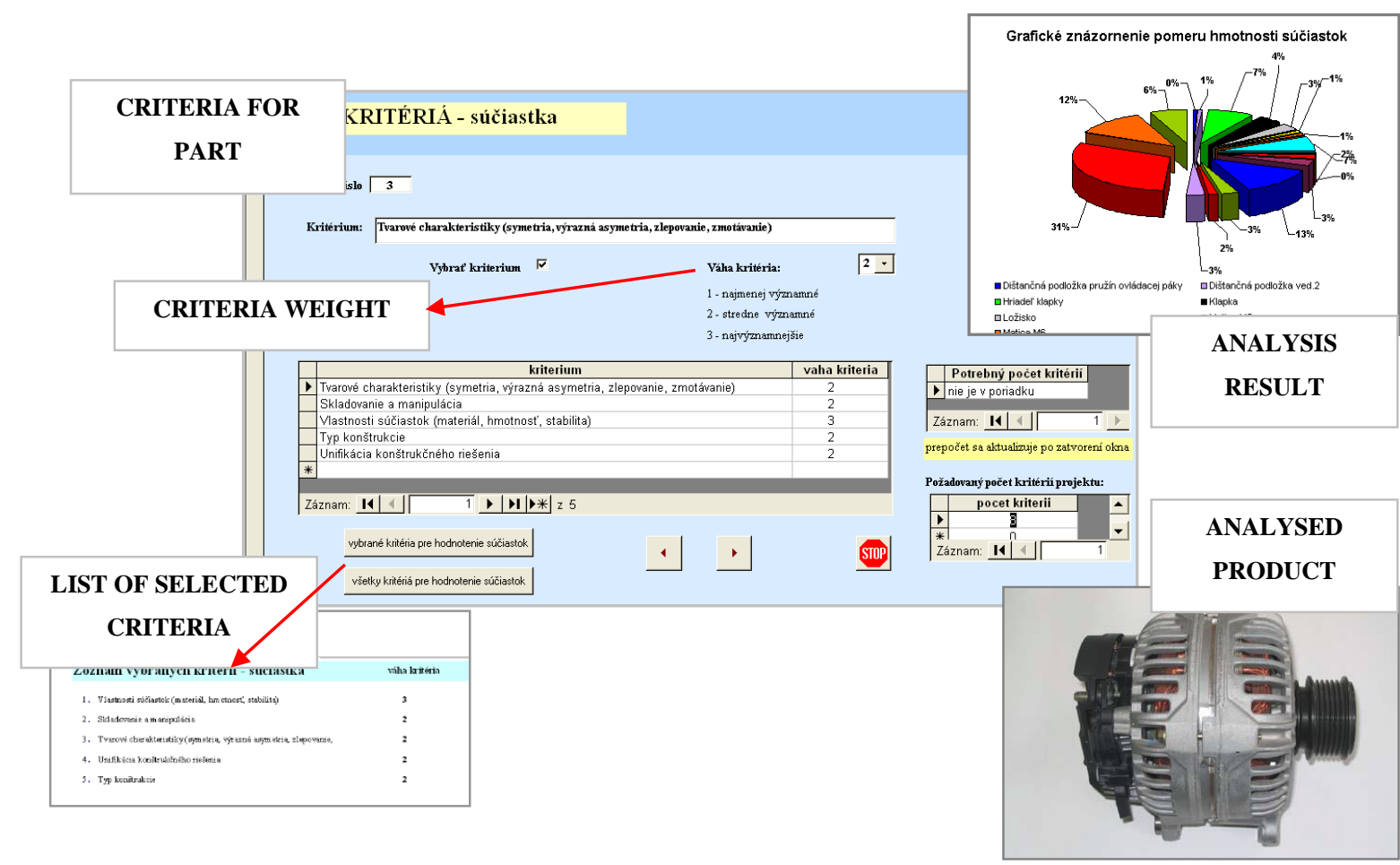

Fig. 1 DFA analysis

\section{ASSEMBLY WORKSTATION DESIGN}

In the field of designing assembly sites, activities are directed to the field of application and verification of existing tools and databases and their mutual compatibility. When designing an assembly site, it is of course necessary to proceed from the analysis of the prefabricated product through the design of the technological process of assembly and selection of technical equipment. For the design of the CATII workstation, several exit sources of 3D element and device models can be successfully used. A great advantage is if the assembled product is designed in CATII. This makes it possible to create a very realistic view of the whole process while also helping to determine the dimensions of individual pallets, trays, clamps and the like.

Ergonomic factors play an important role in the design of hand-held assembly work (3), which results from a person's position in this type of assembly. Inappropriately designed workplace has a negative impact on worker health, productivity and quality of production. Basic tasks of designing such workplaces include the appropriate placement of the work zone, containers, tools and workplace components. This also means the overall layout of the workplace that respects the specific worker performing the given assembly operation (body dimensions, sex, etc.). Comprehensive design of the workplace, taking into account all ergonomic aspects, is demanding and complicated, which ultimately prolongs the design time.

Of course, all available tools offered by the respective CAD system for computer support for site design are used. One of these tools is the ergonomic analysis of RULA-based assemblies.

Dassault Systemes' CATIA system includes modules that support the whole lifecycle of the product from design through detailed modeling and product drawings including product group design to service and maintenance. This system also includes integrated ergonomic design and analysis modules. Fig. 2 shows an example of an ergonomic analysis performed in CATII on a one-piece flow workbench for alternator assembly. 


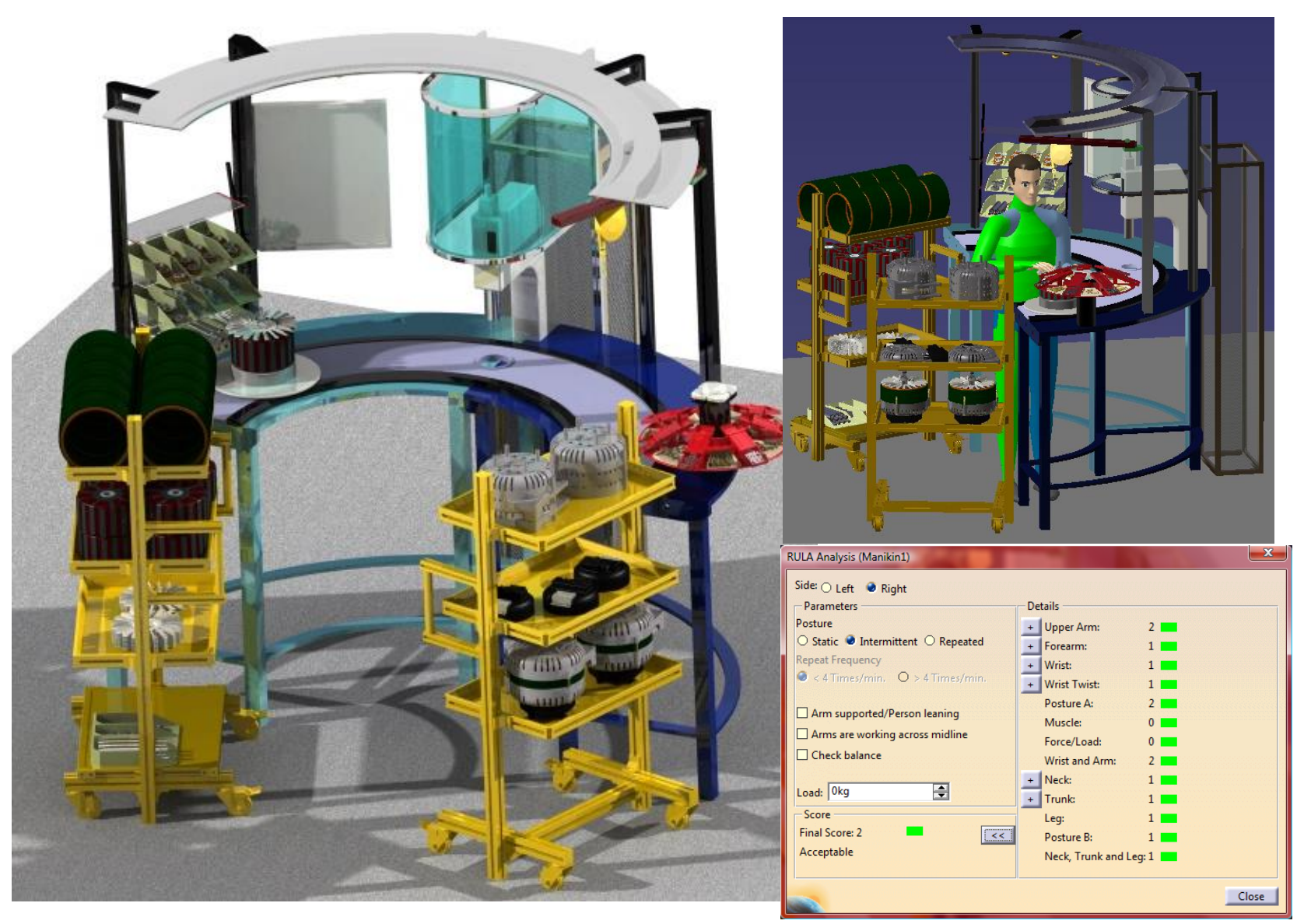

Fig. 2 Ergonomic analysis of the one-piece flow workstation for manual assembly of the alternator (2)

\section{VIDEO ANALYSIS}

The basis for support for increasing the efficiency of assembly processes is analysis. This analysis involves examination of the sequence of operations, their kind, speed and frequency of movements, the distribution of pallets, containers, blanks, tools and other technical elements. One of the possibilities of analyzing the assembly operations is to capture the video of the installation operations performed. The video image actually captures the sequence and time of the operation, it can be played replayed and it also played slowly, allowing you to notice the details that are not obvious in the ordinary view. In order for the video to be the most accurate source of information, it is necessary to pay attention to the video capture and to keep in mind some limitations that are associated with video capturing. The most common way to analyze a video is to analyze it using a software product. An example is the Avix software package of the Swedish company Solme AB or the AOA software developed within the framework of research at the Department.

AOA - Assembly Operation Analysis has been developed within the framework of the research. Detailed information can be found in $(4,5)$; Fig. 3 illustrates an example of a video analysis of the installation of a ventilation grille for a passenger car. 


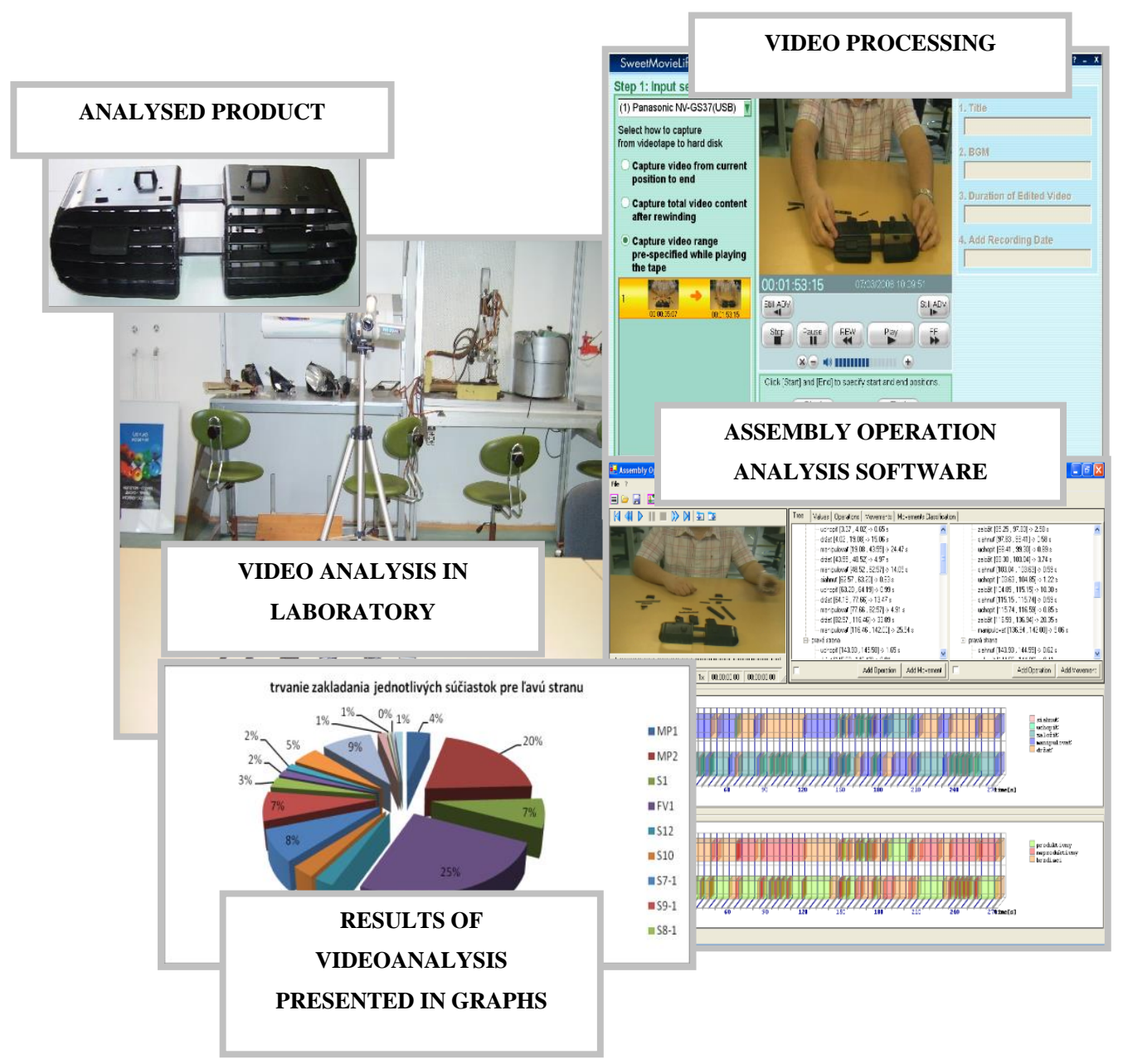

Fig. 3 Video analysis of ventilation grid

Based on the results, it can be said that the main areas of the video analysis application include:

- Assessment of the impact of the design change on the assembly time and the structure of the assembly operations,

- Assessment of several product variants in terms of their fitting ability,

- Assessment of the impact of changes in the design of tools, preparations and containers used over time and the structure of assembly operations,

- Assessment of the impact of the installation of the new equipment, component or preparation on the time and structure of the assembly operations,

- Assessment of the impact of changing work organization and / changes in the technological progress of the assembly over time and the structure of operations,

- Considering several variants of the solution or the entire assembly process, or some part of it (e.g. multiple trays, etc.)

- Comparison of time data obtained in the design process, the MTM method with the real time gained at the experimental workplace, respectively, directly in production,

- Scanning to support training or retraining new workers in a real production process,

- Supporting research and development activities aimed at, for example, to create a custom classification of basic assembly operations and operations with application of time data,

- Sensing to identify critical assembly points of the product, for statistical purposes. 
Virtual reality is one of the major directions in both product design and manufacturing. In the automotive industry, it is used both in car development, where car design is presented and verified in virtual reality, but can also used in the design and verification of automotive production processes, verifying the assembly of parts. Virtual reality is used mainly in product development phases, but it also finds application in retrospective verification of real processes and processes. Fig. 4 illustrates an example of a CyberGlove II data gadget application.

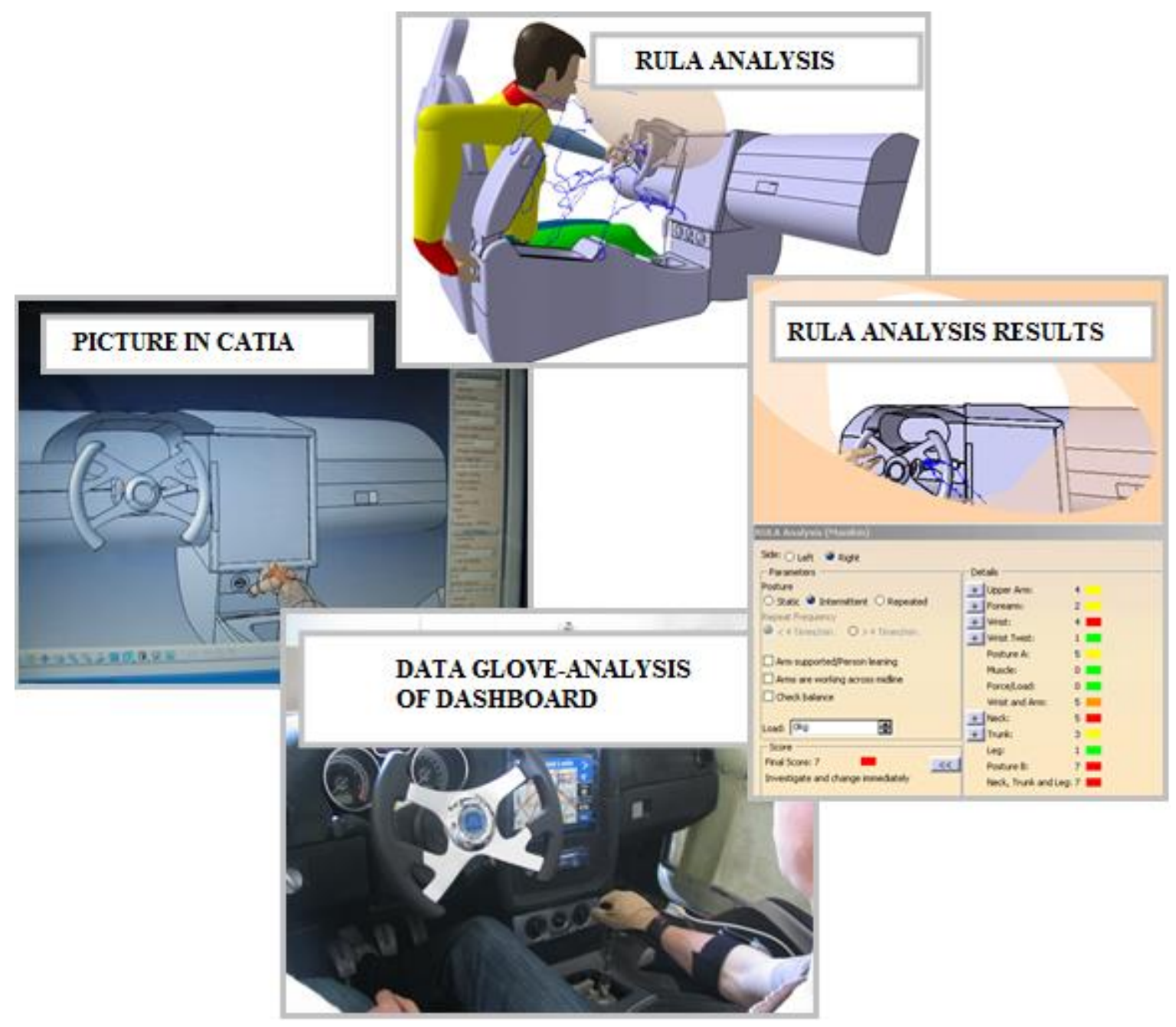

Fig. 4 Virtual reality - dataglove application

In the development of the so-called student car has been designed the instrument panel and the center panel of the car. The data gauntlet was used to verify the design ergonomics. A user with a hand grip, who used the various controls in the car (air conditioning control, speed shift, touchscreen, etc.) was seated in the car. Using the Data Glove, the trajectory of the movement of his hand was transferred to the computer. The trajectories were used in the virtual environment to accurately position the mannequin's hand, i.e., hand position of mannequin precisely corresponds to the real position of the user's hand when operating the respective button. After re-positioning, ergonomic analyses (RULAs) were conducted to determine whether the user position is appropriate and comfortable.

In the same way, it is possible to analyze the assembly procedures in the automotive industry and then, based on the analyses results, to optimize the workplaces in order to reduce the burden on the workers, increase the productivity and quality. For more details on the application of the Data Glove, see (6). 


\section{CONCLUSION}

Proper application of the above tools can be very helpful in designing such products and assembly workplaces that consider the requirements of simple and cost-effective assembling as well as ergonomic requirements. Research continues in this area, because as new materials and production technologies are being developed, assembly technologies need to be adapted accordingly.

\section{Acknowledgements}

This contribution is the result of the VEGA 2/0113/16 Project supported by the scientific grant agency of the Ministry of Education, Science, Research and Sport of the Slovak Republic, and of the Slovak Academy of Sciences.

\section{References:}

1. PETERKA, J., SENDERSKÁ, K., VÁCLAV, Š. POKORNÝ, P. 2008. Product design suitable for assembly. In: Annals of DAAAM for 2008 \& Proceedings of the 19th International DAAAM Symposium. Vienna: DAAAM International, pp. 1063-1064. ISBN 9783901509681

2. SENDERSKÁ, K. 2010. "One-piece - flow” princíp a jeho aplikácia v montáži. ("One-piece flow" principle and its application in assembly). Transfer inovácií (Innovation transfer), No. 16, pp. 258-261. ISSN 1337-7094

3. MAREŠ , A. SENDERSKÁ, K. 2008. Application of Catia ergonomic modules to manual assembly workstation optimization. In: RaDMI 2008, pp. 708-713. ISBN 9788683803248

4. MAREŠ, A. SENDERSKÁ, K. 2006. Capturing video of assembly operations for analysis purpose. In: RaDMI 2006. Trstenik, High Technical Mechanical School of Trstenik. ISBN 868380321X

5. KOVÁČ, J., MAREŠ, A. SENDERSKÁ, K. 2005. The concept of video analysis for the support of manual assembly operation design. In: PRO-TECH-MA '05. Rzeszów : Politechnika Rzeszowska, pp. 245-247, ISBN 8371993560

6. MAREŠ, A. KOVÁČ, J.LIBA, M. SENDERSKÁ, K. 2010. Virtuálna realita - aplikácia dátovej rukavice pri riešení vybraných úloh. (Virtual Reality - application of data glove to solve selected tasks). Uspěch: produktivita a inovace $v$ souvislostech (Success:context of productivity and innovation), No. 4, pp. 10-12. ISSN 1803-5183

\section{ORCID:}

Štefan Václav 0000-0003-3266-3645 